But of all control methods, herbicides have the brightest future. Among those listed by Mr Robson as having been cleared under the Pesticides Safety Precaution Scheme are 'Dalapon', which is especially active against reeds and other grass-like weeds on river banks; 'Diquat', which is active against submerged weeds; and maleic anhydride, which inhibits plant growth without actually killing the plants.

\section{Comprehensive Planning}

"GoING comprehensive" raises considerable building problems. Following up the Department of Education and Science comment (circular 10/65) that the "disposition, character and size of existing schools" must be taken into account when the change is made, the Architects' Department at the DES has devoted its latest bulletin to the problems, architectural and educational, involved in such a change (Comprehensive Schools from Existing Buildings, Building Bulletin 40, HMSO, 16s.).

The bulk of the bulletin is taken up with five case studies which cover the possibilities of amalgamation of two or more schools with some new buildings, the enlargement of schools of different sizes, and the first stage of a new school which, until further building is possible, uses some old buildings on a different site. The bulletin also briefly rehearses various problems of organization of pupils into groups; accommodation for pupils, administration, and staff; sites; and circulation and storage space. Considerable emphasis is laid on the importance of examining all the possibilities in detail, even though some of them may eventually be rejected. This preliminary section covers a lot of ground but is necessarily short on detail.

As well as suggestions to architects about possible alternative uses for space, there is a plea for the educators to give clear guidance to architects on future teaching requirements. The document stresss that the problem of working accommodation has to be examined as a whole and cannot merely be a sum of the requirements of the individual teachers. Compromise is inevitable, and it is up to the staff, knowing the limitations of time and supply of teachers, to work out a balanced curriculum before sensible accommodation schedules can be produced. If, as is recommended by the DES, the form of reorganization of secondary education in a particular area is to depend on the suitability of existing schools for amalgamation and adaptation, then local authorities should be aware of the factors involved, and it is hoped that this bulletin will indicate some of the questions which should be asked before reorganization is begun.

\section{Persuading Postgraduates}

LAST week saw yet another of the courses aimed at persuading the academically minded that work in industry is not so bad after all. The course is the third graduate school to be organized by the Science Research Council and the Careers Research and Advisory Centre, and was attended by 100 science and technology PhD students working in the universities. It was held in association with the Manchester Business School at the University of Manchester, and is meant to introduce the $\mathrm{PhD}$ students to the variety of problems existing in industry and administration, and the ways in which they are solved. The organizers hope to do this by using the methods of the business schools-the business game, project work and a case study.

The latest graduate school is the first in the series to be run in association with the Manchester Business School; previous courses have been associated with the London Business School. For this reason the Manchester course has a slightly different emphasis. It relies less on case studies, and has as its central exercise a research project on the implications of the introduction of the electric car. $\mathrm{Mr}$ Alan Pearson, of the Manchester Business School, who is Director of Studies at the graduate school, says the work done on the electric car project by the PhD students may well be worth publishing. 'The course membership also includes 28 science and technology PhDs already working in industry and public service organizations, from whom the organizers hope the students will gain a favourable insight into the industrial situation.

One of the difficulties in holding a course of this kind is to judge how successful it has been in changing what are often firmly fixed prejudices. Some information about this may shortly become available. The London Business School, at a similar course held last year, used a questionnaire to gauge the attitudes tc, industry among the participants both before and after the course. The results of the investigation should help in evaluating the success of the venture.

\section{Risks of Radiation}

THE use of radiation techniques is becoming increasingly common in industry, medicine, research and toaching. But, like other industrial risks, the danger's attached to radiation are subject to legal controls which set acceptable limits. The instruments used to monitor radiation must be accurately calibrated, not because the measurement of radiation needs to be extremely accurate but because it is important that any errors associated with instruments, or any interpretation they require, shall be known. This task of calibration is carried out by the Central Electricity Generating Board Dosemeter Calibration Facility at Berkeley Nuclear Laboratories in Gloucestershire.

The facility was built in 1961, and its primary function is to calibrate the instruments used to monitor radiation at CEGB power stations. The capital costs were high, principally because they included a $400 \mathrm{kV}$ accelerator and a $250 \mathrm{kV} X$-ray set. The facility is run by Mr I. M. G. Thompson and a staff of three, who calibrate nearly 1,000 instruments a year. Arrange. ments are now being made to make the service available to anybody who needs it, for a charge of about $£ 60$ for a complete calibration; already more than 50 instruments a year are calibrated for outside organizations.

The standards and techniques used for calibration for radiological purposes are a little unusual, because the risks of radiation are related to dose in different parts of the body rather than to any fundamental properties of the sources or materials involved. For electromagnetic radiation it is possible to relate dose to the unit known as exposure with only limited accuracy, and only in the range between $20 \mathrm{keV}$ and a few $\mathrm{MeV}$. Accurate estimates are therefore rarely justified, but an approximate upper limit to dose is usually sufficient. For neutrons, there is no simple 
concept analogous to exposure, so measurements must be expressed either in terms of fundamental quantities such as fluence and energy, or else by means of an instrument whose response is modified so that under specified radiation geometries the meter reading gives an approximate estimate of the dose delivered by all neutrons irrespective of energy.

The CEGB has a range of equipment for producing electromagnetic radiation and neutrons. Electromagnetic radiation is produced by sealed radioactive sources and by X-ray sets whose beams can be filtered to give narrow spectra. Neutrons are produced by a range of sealed sources, and by the $\mathrm{D}(\mathrm{d}, \mathrm{n}) \mathrm{He}$ and $\mathrm{T}(\mathrm{d}, \mathrm{n}) \mathrm{He}$ reactions. Thermal neutrons are available by moderating the $2.5 \mathrm{MeV}$ beam produced by the first of these reactions.

Experience with the facility has shown that many instruments have undesirable features which would have been impossible to identify without comprehensive radiological investigation. Some instruments, for instance, fall back to less than full scale at very high intensities, and some neutron instruments respond to gamma radiation of high intensity or high photon energy. Manufacturers sometimes introduce design changes with serious radiological consequences, and even the best instruments seem to develop faulty characteristics during their lifetime. But, apart from the need to identify faults, the principal task of the facility is to adjust instruments so that their scales read as accurately as possible, and to ensure that the user has all the information needed to interpret the scale reading correctly.

\section{Safety Testing}

THE collapse of the North Sea drilling rig Sea Gem and the cause of the Michael Colliery fire were two of the more spectacular investigations undertaken by the Safety in Mines Research Establishment during 1967, but the work of the establishment, under the Ministry of Power, covers every safety problem in the mines, including breathing appliances, methods of detecting mine gases and both gas and dust explosions. The work of the SMRE, under H. T. Ramsey, the director, is reported in the 1967 annual report (HMSO, 8s. 6d.).

Because of the SMRE's research in metallurgy and fatigue strengths, the establishment was asked to examine tie bars from the Sea Gem after it sank, killing 13 men. The bars were found to have been flame-cut from mild steel plate, which produced brittle areas under the cut surfaces. Some of the flame grooves had been filled with weld metal which extended the brittle areas. The results presented to the public inquiry concluded that "failure of tie bars ... was the most probable prime cause of the collapse".

The fire at Michael Colliery caused the death of nine men and was one of the most serious in recent years. Although it was impossible to investigate the site, the fire is known to have spread rapidly, and the section of roadway first affected was lined with polyurethane foam to reduce the emission of fire-damp into the roadway and the leakage of air out of the roadway into the waste. Further investigations have shown that, even though the foam contains a flame-retarding agent, it is still potentially highly flammable and needs to be covered with an incombustible coating such as asbestos cement.
Other preventive work at the establishment included studies of various types of self-rescuers which are to be adopted generally by the National Coal Board. Models produced in Germany have been fitted with a heat exchanger which keeps the temperature of the inspired air within a tolerable range, a great improvement over previous devices. More work needs to be done, however, on reducing breathing resistance and allowing for the presence of dense smoke. Improvements have also been made in techniques for measuring airborne dust by light-scattering methods, and a laser system has been developed that can measure both particle concentration and size distribution in a dusty atmosphere.

\section{Green Light for Reform}

AT last the administrative structure of the National Health Service may get the shake-up which most people agree it badly needs. At least, in a Green Paper published last week, Mr Kenneth Robinson, the Minister of Health, has set out briefly but clearly some reforms (National Health Service: The Administrative Structure of the Medical and Related Services in England and Wales, HMSO, 3s. 6d.). Everybody will be interested to see how well his kites fly.

The main theme of the paper is that the functions of the present hierarchy of committees-involving executive councils, regional hospital boards and boards of governors with their hospital management committees-should be replaced by a single authority in each area and that area authorities should be responsible for some important functions which are now in the hands of the local authorities. The present tripartito system is generally criticized for failing to provide the necessary coordination between the numerous services, and few tears are likely to be shed over its disappearance.

Mr Robinson envisages the whole new set-up as consisting of some 40 to 50 area health boards, each covering a large area and "having full scope for tho efficient and imaginative development of comprehensive services". These services would include various hospital and specialist services; community and local health services; general medical and dental practice, and the ophthalmic and pharmaceutical services as well as clinical teaching, postgraduate medical education and specialized services. Public health services would also be drawn into the general scheme. Each area board would have fifteen or sixteen board members, but the actual running and organization of services would be carried out by an exccutive formed by the senior officials of the five departments constituting each area board. One particularly welcome proposal is that the present largely lay administrative staff should be replaced by people with a broad professional knowledge of medical and related services. In areas with medical schools one or two additional members might be appointed to the boards on the nomination of universities. $\mathrm{Mr}$ Robinson maintains that central Government would retain its "guiding role", but that the area boards would on the whole be allowed to manage their own affairs without interference. The function of the Minister of Health would be to lay down general principles and to secure the coordination of services administered by the separate area boards. Mr Robinson's statement that such a transfer of re- 